\title{
Development and analysis of 11-year MODIS forest fire datasets across the Heilongjiang Province of northeastern China
}

\author{
DENG Ou ${ }^{1,2, a}$, SU Guofeng ${ }^{1, b, *}$, HUANG Quanyi ${ }^{1, \mathrm{c}}$ and LI \\ Yiqiu $^{2,3, \mathrm{~d}}$ \\ ${ }^{1}$ Institute of Public Safety Research, Department of Engineering Physics, \\ Tsinghua University, Beijing 100084,China \\ ${ }^{2}$ Ecological Security and Protection Key Laboratory of Sichuan Province, \\ Mianyang Normal University, Mianyang 621006, China \\ ${ }^{3}$ Institute of Geographical Sciences and Natural Resources Research, \\ Chinese Academy of Sciences, Beijing 100101, China \\ ${ }^{a}$ cnfly@foxmail.com, ${ }^{b}$

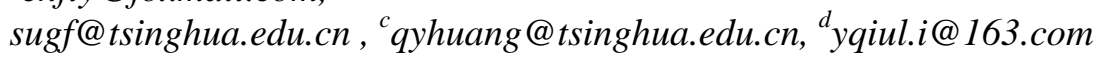 \\ *Corresponding author.
}

\begin{abstract}
.
Forest fires are a recurrent environmental and economic emergency worldwide. To date, fire activity and its impact were addressed by most international projects. In this study, we processed MCD45A1, MOD13Q1, and in-situ monitoring history fire records for mapping and validating burn scars covering the Heilongjiang Province of northeastern China. Burned areas across this area and a coherent long-term forest fire inventory over a period of 11 years (2000-2010) were developed, focused on analysis of the spatial and temporal variations of forest fire occurrence and burn scars during fire seasons. The analysis showed that fire season in the spring long for three to four months due to the lowest relative humidity. There were hardly forest fires occurrence in the summer unless drought. Fire season in the fall is only 1-2 months. Over half of the burned areas were in Taiga Forest Region (53.68\%), and about $44.00 \%$ of the burned areas were in Temperate Mixed Forest Region, while a little of the burned areas were in the Temperate Steppe Region (only 2.32\%). The vast majority of forested area had a middle elevation $(200 \mathrm{~m} \leqslant \mathrm{~h} \leqslant 500 \mathrm{~m})$ with gentle slopes $\left(\leqslant 5^{\circ}\right)$. So, development and analysis of a time series of burned areas in forests based on satellite remote sensing would help elucidate the relations and interactions among the fire activities and climate change, topography, vegetation type, and landform, and also would service for forest fire emergency management and decision-making policies
\end{abstract}

Keywords: fire frequency; Fire history; Fire intensity; MODIS 


\section{Introduction}

Forest fires are global, multinational major natural disasters, and forest fires are prominent changes agent affecting ecosystem structure as well as the cycling of carbon and nutrients are globally-significant causes of greenhouse gas emission[1,2]. Since 1980s, forest fires caused by global warming appeared to be on the rise. The area of forest fire has not reduced accordingly although countries continue to increase forest fire control costs. To date, most international projects are addressing fire activity and its impact, with initial emphasis on savanna burning in southern Africa and deforestation burning in tropical zones, especially in Brazil[3,4,5,6]. However, Fires in boreal and temperate forests also play a significant role in the global carbon cycle[7,8]. Large areas of the world's boreal and temperate ecosystems, which natural fire has shaped over millennia, are also burned annually. Although fire activity in the boreal and temperate ecosystems is not as wide-spread as in tropical ecosystems, its impact on land cover lasts longer due to slow growth rates. Development of forest fires were influenced by time and geographical conditions, which shows significant temporal and geographical rules. So, mapping the timing and the extent of forest fires is important. The long historical archive at a spatial resolution suitable for regional-scale studies and such dynamic information is also crucial for forest fire emergency management and decision-making policies.

Heilongjiang Province, as a big forestry province of China, is also a significant part of northern Eurasia boreal forests zonation because of its abundance of forests resources. we processed MCD45A1(a monthly Level-3 gridded 500-meter fire burned area product), MOD13Q1 (a 16-day Level 3 250-meter vegetation indices product) , and in-situ monitoring history fire records covering the Heilongjiang Province of northeastern China and developed a coherent long-term forest fire inventory over a period of 11 years (March through October from 2000 to 2010), focused on analysis of the spatial and temporal variations of forest fire occurrence and burn scars during fire seasons.

\section{Study Area and Datasets}

Study Area. Heilongjiang Province locates the northeast frontier of China. It is an important component of Eurasia boreal forests zonation because of its abundance of forests resources, its zonal vegetation is taiga and temperate mixed forest, which occupied the most natural forests in whole country. As a big forestry province of China, Heilongjiang Province is also a significant part of forest zone in northern Eurasia. Heilongjiang province, in which average annual forest fire burned area ranks the first in China, is China's most serious fire hazard areas.

Datasets. The Moderate Resolution Imaging Spectroradiometer (MODIS) possesses the most useful channels for forest fire monitoring and mapping. Nowadays, MODIS has more than 10 year's history and has sufficient temporal 
sampling, which is enough to exploit the long historical archive at a spatial resolution suitable for regional-scale studies. We processed MCD45A1 (a monthly Level-3 gridded 500-meter fire burned area product) and MOD13Q1 (a 16-day Level 3 250-meter vegetation indices product) to analysis the spatial and temporal variations of burn scars during fire seasons in Heilongjiang Province. History in-situ fire records, topographic data, vegetation regions and landforms vector data were also employed for the study.

\section{Data Processing System, Algorithms and Analysis Methodology}

Data Preprocessing. Data preprocessing were carried out in the MODIS Reprojection Tool (MRT) and Cygwin. In the data preprocessing stage, images were batch processed. MCD45A1, MOD13Q1 images acquired in different satellite orbits (including tile h25v03, h26v03, h26v04, h27v04) were reprojected, resampled, mrtmosaiced and subset (spatial subset and spectral subset) into one image based on a criterion of minimum satellite zenith angle in the overlapped areas of the images.

Burnt Area Data and Validation. Burnt area data were derived from the MCD45A1 burned area product. The burnt data contains the location of the burned pixels, and the day of burning. In this study, the MOD13Q1 vegetation indices products are used to identify potential burned pixels. MOD13Q1 vegetation indices products had been pseudo-colored to compare with the burn scar derived from the MCD45A1. Pixels passing the specific NDVI thresholds were connected to create burned scar patches. Any patches that contain no confirmed hotspot pixels were removed. Fig.1 shows a burned area comparing of history in-situ fire records and MCD45A1 burned area in Julian day. There is a reasonable agreement with the correlation coefficient equal to 0.85 .

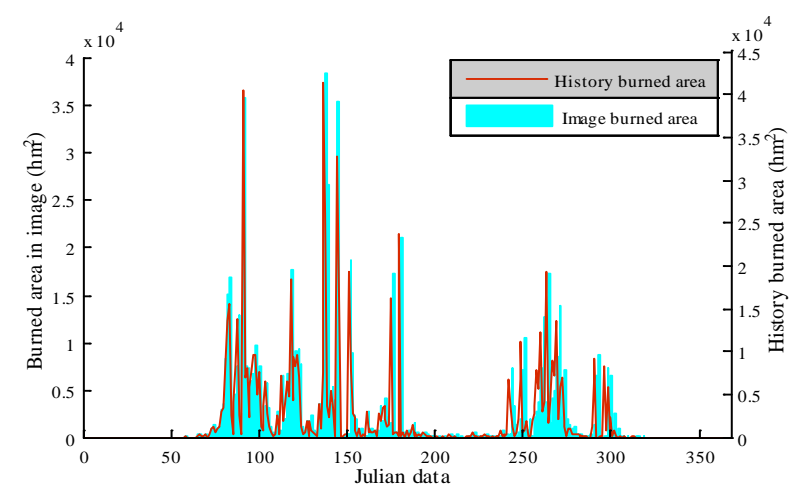

Fig.1. A burned area comparing of history and image in Julian date 
In this way, 11 year's yearly dataset and 11 year's monthly dataset were created based on the burnt area data. Fig. 2 shows the 11 year's interannual burn scar variability over three vegetation-regions and over five landforms. Fig. 3 shows the 11 year's monthly burn scar variability over three vegetation-regions and over five landforms.
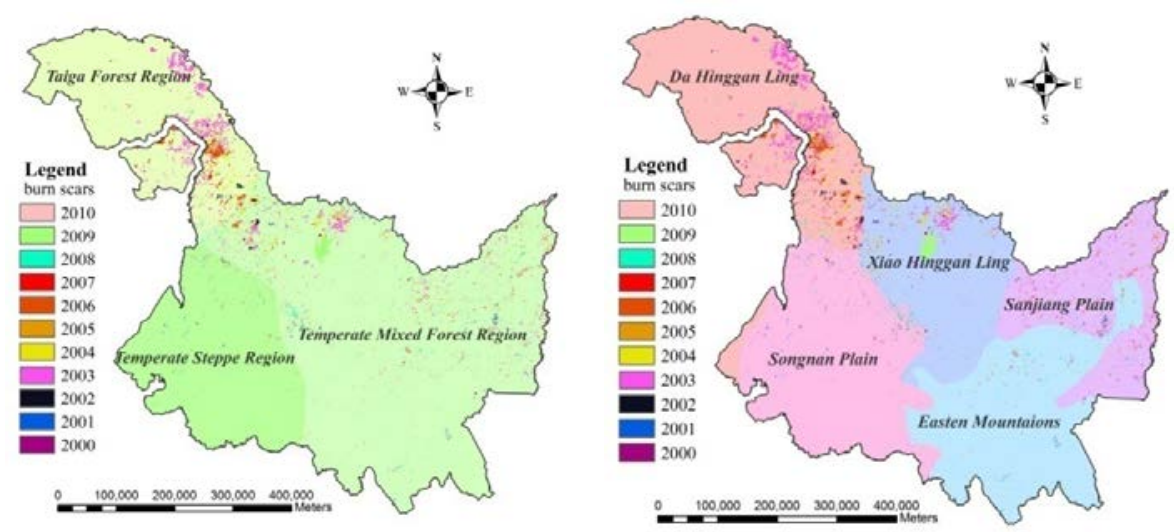

Fig.2. 11 year's interannual burn scar variability over three vegetation-regions(left) and over five landforms(right)
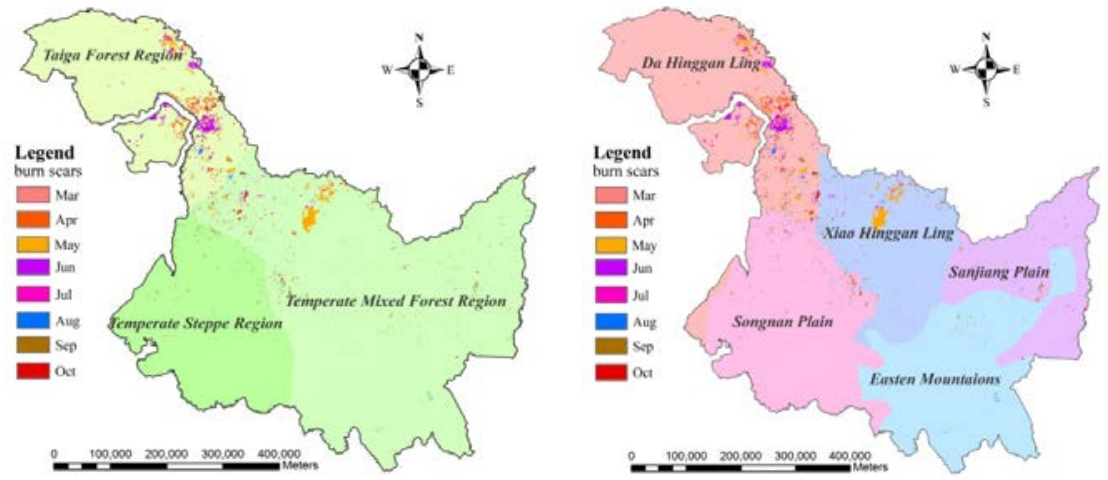

Fig.3. 11 year's monthly burn scar variability over three vegetation-regions(left) and over five landforms(right)

\section{Results of Monitoring Indictors}

Interannual Variation Characteristics. The spatial distribution and temporal variation of mapped burned areas fluctuated drastically from one year to another (Fig. 4). 2003 was the most active years of burning with a total area of 822900 $\mathrm{hm}^{2}$, which was not shown in Fig. 5 because the burned area was too large to 
harmonious with the other years. By contrast, only $61347 \mathrm{hm}^{2}$ was burned in 2010 . This finding was consistent well with the Heilongjiang province fire statistics.

Further examination of the burn scar areas in the three vegetation-regions (Fig. 4 left) revealed that major burned areas were distributed throughout Taiga Forest Region, followed by Temperate Mixed Forest Region. Over half of the burned areas were in Taiga Forest Region (53.68\%), and about $44.00 \%$ of the burned areas were in Temperate Mixed Forest Region, while a little of the burned areas were in the Temperate Steppe Region (only 2.32\%).

The landforms over Heilongjiang Province were also used in this study. According to the landforms, Da Hinggan Ling was the major burned area, and about $64.74 \%$ of the burned areas were in there, Xiao Hinggan Ling was about $23.49 \%$, while other areas were no more than $5 \%$ of the burned areas (Fig. 4 right).
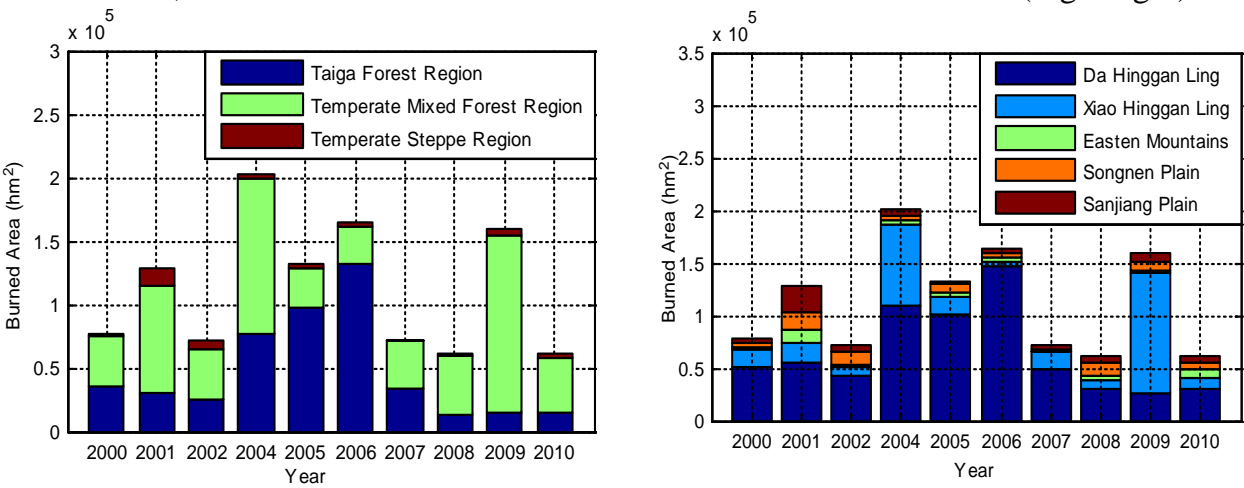

Fig.4. Interannual burned area variability over three vegetation-regions(left) and over five landforms(right)

Monthly Variation Characteristics. Monthly burned areas were computed from March through October and were accumulated to obtain yearly burned areas. Most years, most of the region of Spring is cranking the wind, high temperature, high grade forest fire. Fire season in the Spring long for three to four months due to the lowest relative humidity over the forest area under the conditions. Summer is rainy season; generally don't happen forest fire unless drought, but high temperature and strong convection, which induce lightning, are two major weather factors causing active fires in the summer season. Most lightning events occur in summer, especially over the boreal forests in Da Hinggan Ling. Fire season in the fall is short, only 1-2 months, this is a forest vegetation yellow season, in certain meteorological conditions, fire spreading rapidly, can also cause a big forest fire.

The monthly burned areas variation of the 11 years over Heilongjiang province is shown in Fig.5. Of the 8 months, April, May, and September are the most active 
burning months (19.40\%, 46.42\%, and $12.28 \%$ of burning), while the other months' burned areas relatively small, minimum burning occurs in March (3.24\%). June, July, August and October were 5.29\%, 4.10\%, 5.01\% and 4.26\%.

Further examination of the monthly burn scar areas in the vegetation-regions (Fig.5 left) revealed that the most active burning was more focused on Taiga Forest Region in May, which concentrated about $53.58 \%$ of the burning. For the Temperate Mixed Forest Region, it's about $41.05 \%$ of the burning concentrated in May. Furthermore, Taiga Forest Region and Temperate Mixed Forest Region each concentrated about $19.14 \%$ and $19.69 \%$ in April, while in September, Temperate Mixed Forest Region concentrated about 19.03\%, Taiga Forest Region only 4.35\%. So, Temperate Mixed Forest Region more prone to forest fire than Taiga Forest Region in September.

According to the landforms, the most active burning in May was more focused on Da Hinggan Ling, which concentrated about $64.09 \%$ of the burning, and about $32.47 \%$ of the burned areas in May were focused on Xiao Hinggan Ling. In April, Da Hinggan Ling concentrated about $49.21 \%$ of the burning, Xiao Hinggan Ling concentrated about $43.12 \%$, no more than $10 \%$ of the burning concentrated in other areas. The detail monthly burn scar areas in other landforms were shown in Fig. 5(right).
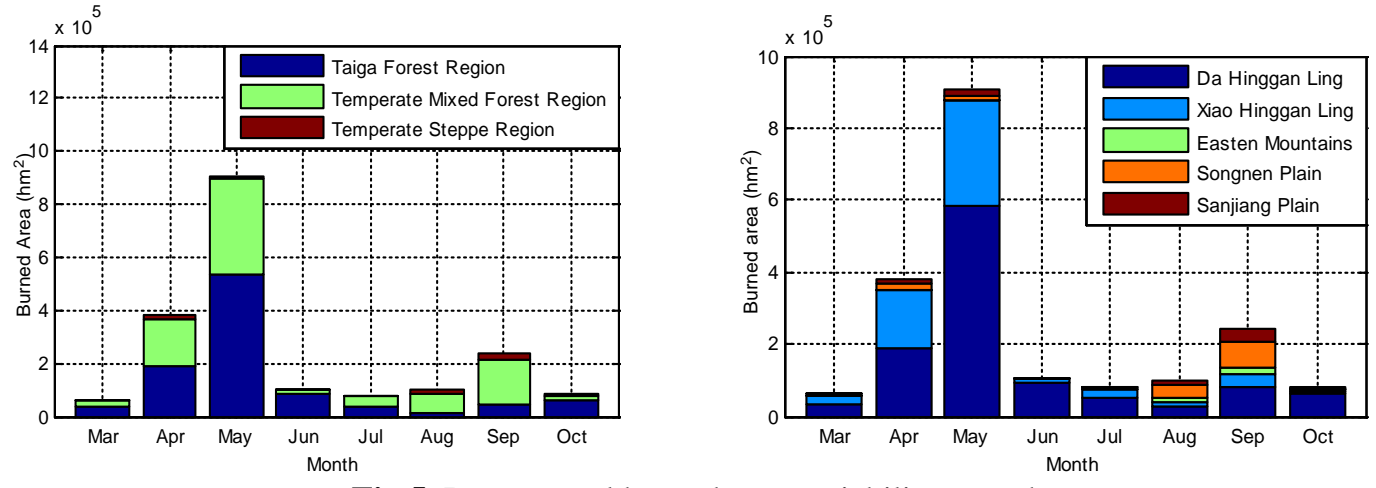

Fig.5. Intra-annual burned area variability over three vegetation-regions(left) and over five landforms(right)

Topographic Variation Characteristics. Fig.6 (left) shows that the vast majority of forested area had a middle elevation $(200 \mathrm{~m} \leqslant \mathrm{~h} \leqslant 500 \mathrm{~m})$. The middle elevation stands had more frequent burning than lower and higher elevation stands. In the highest elevations ( $\mathrm{h}>1000 \mathrm{~m}$ ), the poor soil and moisture conditions resulted in fewer fuels and thus limited fire ignition and spread, but the relative burning rate 
was relative higher since the highest elevations areas was small. The vast majority of fires occurred in regions with slopes less than $5^{\circ}$ (Fig. 6 mid), and its burning rate was also the highest. With the increase of slope, the burn scar area and burning rate decreased gradually (Fig.6 mid). There was no clear dependence on the aspect of a slope both in terms of absolute burn scar area and the relative burning rate (Fig.6 right) although aspect had been considered as a factor in rating fire risk at local scales.

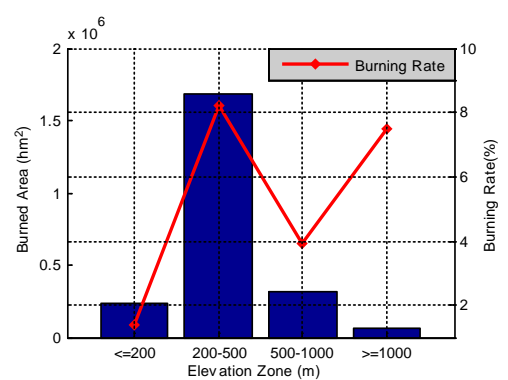

Fig.6. Burned area in different elevation zones (left), slope (mid) and aspect (right) classes. Relative burning rates are shown in the curves

\section{Conclusions}

Based on ARCGIS spatial analysis tools, we analyzed interannual and intra-annual fire variability over three major forest types and five landscape areas. Topography influence of fire occurrence, burned area and burn rate for the different elevation zones, aspect classes, and slope classes were also analyzed.

The spatial and temporal variation in fire activity was mainly influenced by climate, fuel types and topography. Relative humidity and temperature were important climate factors causing active fires. So, fire season in the spring long for three to four months due to the lowest relative humidity. But summer for rainy season, generally didn't happen forest fire unless drought. Fire season in the fall was short, only 1-2 months, while in certain meteorological conditions a big forest fire could also be caused. Over half of the burned areas were in Taiga Forest Region (53.68\%), and about $44.00 \%$ of the burned areas were in Temperate Mixed Forest Region, while a little of the burned areas were in the Temperate Steppe Region (only 2.32\%). Da Hinggan Ling was the major burned area where about $64.74 \%$ of the burning took place. Xiao Hinggan Ling was about 23.49\%, while other areas were no more than $5 \%$ of the burned areas. The vast majority of forested area has a middle elevation $(200 \mathrm{~m} \leqslant \mathrm{~h} \leqslant 500 \mathrm{~m})$ with gentle slopes $(\leqslant$ $5^{\circ}$ ). There was no clear dependence on the aspect of a slope both in terms of 
absolute burn scar area or the relative burning rate, and the cause wasn't clear explain in the paper.

Based on this study, a general understanding was reached that satellite remote sensing is particularly suited for monitoring forest fire activities. MODIS active fire products provide a resourceful tool for forest fire emergency management, and MODIS active fire products have sufficient temporal sampling, which are enough to exploit the long historical archive at a spatial resolution suitable for regional-scale studies. The spatial and temporal forest fire mapping is also useful for many decision-making policies.

\section{Acknowledgements}

This work was financially supported by National Natural Science Foundation of China (No. 91024017), the National Key Technology R\&D Program (No. 2011BAK09B01), State Key Program of National Natural Science of China(No. 91224004), Mianyang Normal University Doctor Startup Fund(No. QD2013A09).

\section{References}

[1] J. Beringer, LB Hutley, NJ Tapper, A Coutts, A Kerley, AP O'Grady: International Journal of Wildland Fire. Vol. 12 (2003), p. 333-340.

[2] A. S. Isaev, G. N Korovin, S. A Bartalev, D.V Ershov, A Janetos, E. S Kasischke: Climatic Change. Vol. 55(2002), p. 235-249.

[3] J. Trentmann , R. J. Yokelson: Journal of Geophysical Research-Atmospheres. Vol.110(2005), p.236.

[4] J. Russell-Smith, B. P. Murphy: International Journal of Wildland Fire Vol.18(2009), p.1-18.

[5] C. Takahata, R. Amin: Environmental Management . Vol.45(2010) , p. 414-423.

[6] G. R.Van der Werf,, J. T. Randerson: Atmospheric Chemistry and Physics. Vol.10(2010), p. 11707-11735.

[7] F. Mouillot, A. Narasimha, Y. Banlkanski, J.F. Lamarque, C.B. Field: Geophysical Research Letters. Vol. 33(2006), p. 16.

[8] K. S. Pregitzer, E. S. Euskirchen: Global Change Biology. Vol. 10(2004), p. 2052-2077. 